\title{
Teaching
Methods
}

\section{Plant Science Graduate Students: Demographics, Research Areas, and Recruitment Issues}

\author{
Rebecca L. Darnell ${ }^{1}$ and Jimmy G. Cheek ${ }^{2}$
}

ADDITIONAL INDEX WORDs. agronomy, graduate education, horticulture, plant biology, plant pathology, stipends, student retention

\begin{abstract}
SumMARY. Graduate student enrollment in the plant sciences has decreased over the past several years, and there is increasing interest in recruitment/retention strategies. Before successful strategies can be implemented, however, the status of current plant science graduate programs needs to be determined. Survey data on graduate student demographics, research area, support levels, current recruitment strategies, and career opportunities were collected from 23 plant science graduate programs. Overall, $55 \%$ of graduate students in plant sciences were male and $45 \%$ were female; approximately $60 \%$ were domestic and $40 \%$ were international. Cellular/molecular biology and breeding/genetics were the two disciplines that had the greatest number of graduate students and the greatest number of job opportunities. Although most programs cited financial support as the biggest obstacle to recruitment, there was not a strong correlation between graduate student number/program and stipend amount. However, other funding factors besides stipend amount; such as stipend number, the guarantee of multiple years of support, the funding of tuition waivers, and health insurance costs, likely impact student number. As more of these costs are shifted to faculty, there appears to be an increasing inability and/or reluctance to invest grant funds (which support $60 \%$ of the plant science graduate students) in graduate student education. These data suggest that the decline in plant science graduate student enrollment may not be directly due to low stipend amounts, but rather to shifting of more of the total cost of graduate training to faculty, who may be unable/unwilling to bear the cost. There is also a clear shift in the research focus of plant science graduate students, as postdoctoral and career opportunities are weighted towards molecular biology/genetics, leaving the more applied plant science areas particularly vulnerable to low graduate enrollment.
\end{abstract}

$\mathrm{G}$ raduate education is a vital link between the research and teaching missions of universities, and strong graduate programs are recognized as a priority in attaining

${ }^{1}$ Horticultural Sciences Department, University of Florida, Gainesville, FL 32611

${ }^{2}$ College of Agriculture and Life Sciences, University of Florida, Gainesville, FL 32611.

Florida Agricultural Experiment Station Journal Series R-10684. national and international acclaim. For example, the goal of the most recent University of Florida Strategic Plan (Young, 2002) is to raise the University of Florida into the ranks of the nation's great universities. This is further defined as becoming one of the top 10 public research universities in the nation. In order to do this, the University recognizes the need to increase and strengthen the quality and scope of its graduate programs, and thus has proposed to increase graduate student enrollment from $~ 9500$ in 2002 to $~ 12,500$ by 2010 (Young, 2002). However, there is intense national competition to recruit high quality graduate students, and serious attention must be paid to recruitment, mentoring, retention, and placement of graduate students.

There is the perception among some plant science faculty and administrators that the number of qualified prospective graduate students in the plant sciences is decreasing. Graduate enrollment in agricultural sciences as a whole increased $6 \%$ between 1990 and 1999 (National Science Foundation, 1999). However, graduate enrollment peaked in the mid-1990s, and the number of Master's and PhD degrees conferred in agriculture has decreased $5 \%$ and $8 \%$, respectively, between 1995 and 2000 (U.S. Dept. of Education, 2001a). In particular, graduate degrees conferred in plant sciences decreased 6\% between 1998 and 2000, due primarily to a decrease in the number of $\mathrm{PhD}$ degrees conferred (U.S. Dept. of Education, 2001b). Within the plant sciences, horticulture suffered a $16 \%$ decrease in MS and a 20\% decrease in $\mathrm{PhD}$ degrees conferred between 1998 and 2000 (U.S. Dept. of Education, 2001b). Agronomy and crop science experienced similar decreases in graduate degrees conferred during that same time.

In order to achieve universities' goals of increasing and strengthening graduate programs, and to achieve the goals of many professional societies to increase graduate student membership and involvement (Albrecht, 1998), recruitment and retention strategies that address student needs and current employment opportunities must be developed and implemented. First, however, the current status of plant science graduate programs needs to be described. To address this, a survey was developed to determine plant science graduate student demographics, research area, availability of stipend (or other financial) support, current recruitment/retention strategies, and career placement opportunities.

\section{Materials and methods}

An e-mail survey was developed using methods described by Dillman (2000). Questions pertaining to each of the areas described above were included. Graduate coordinators from 
various plant science programs were identified and the survey was e-mailed to them in Sept. 2003. Follow-up emails were sent as needed.

Graduate coordinators from 29 programs at 16 universities were contacted. Survey data were received from 23 programs at 14 universities (Table 1). All but one (the University of California, Berkeley) were landgrant universities, which were chosen since most plant science programs are in colleges of agriculture. In order to simplify presentation of results, similar programs were grouped under one of four major classifications: agronomy/ crop science, horticulture, plant biology, or plant pathology (Table 2). For example, the plant biology programs at the University of California, Berkeley, the University of California, Davis, and Cornell University are similar to the plant molecular and cellular biology program at the University of Florida. The plant biology programs surveyed focus on basic molecular/cellular biology, while agronomy/crop science and horticulture programs encompass a range of disciplines, from applied to basic plant science/production.

Data were analyzed using Microsoft Excel (Microsoft Corp., Redmond, Wash.) and the SAS System (SAS Institute, Inc., Cary, N.C.). Responses were analyzed over all the plant science programs, or as groups (agronomy/ crop science, horticulture, plant biology, or plant pathology), and means, standard deviations, percentages, and correlations were calculated.

\section{Results}

Plant science programs averaged $19 \mathrm{MS}, 33 \mathrm{PhD}$, and $6 \mathrm{MS}$ non-thesis graduate students in 2003 (Table 3). Agronomy/crop science programs had the largest graduate student enrollment ( 100 students/program), while plant pathology programs had the smallest enrollment ( 40 students/program) (Table 4). Plant biology and plant pathology had greater numbers of students in PhD compared with MS programs, while horticulture and agronomy/crop science programs had similar numbers of students in both degree programs.

Overall, $55 \%$ of graduate students in plant sciences were male and $45 \%$ were female. However, females comprised a lower percent $(27 \%)$ of agronomy graduate students compared with the other programs (Fig. 1A).

Table 1. The universities and plant science graduate programs surveyed in 2003-04.

\begin{tabular}{ll}
\hline University & Graduate programs \\
\hline Cornell University & Crop and soil science \\
& Horticulture \\
& Plant biology \\
& Plant pathology \\
Iowa State University & Agronomy \\
Kansas State University & Plant pathology \\
Michigan State University & Horticulture \\
North Carolina State University & Horticultural science \\
& Plant pathology \\
Ohio State University & Horticulture and crop science \\
Oregon State University & Horticulture \\
Pennsylvania State University & Horticulture \\
Purdue University & Botany and plant pathology \\
Texas A\&M University & Horticultural sciences \\
& Soil and crop sciences \\
University of California, Berkeley & Plant and microbial biology \\
University of California, Davis & Plant biology \\
University of Florida & Agronomy \\
& Environmental horticulture \\
& Horticultural sciences \\
& Plant molecular and cell biology \\
& Plant pathology \\
University of Wisconsin & Horticulture \\
\hline
\end{tabular}

Table 2. Classifications of the plant science graduate programs surveyed in 20032004.

\begin{tabular}{|c|c|c|c|c|}
\hline \multirow[b]{2}{*}{ University } & \multicolumn{4}{|c|}{ Plant science programs ${ }^{\mathrm{z}}$} \\
\hline & $\begin{array}{l}\text { Agronomy/ } \\
\text { crop science }\end{array}$ & Horticulture & $\begin{array}{c}\text { Plant } \\
\text { biology }\end{array}$ & $\begin{array}{c}\text { Plant } \\
\text { pathology }\end{array}$ \\
\hline \multicolumn{5}{|l|}{ AAUy: } \\
\hline Cornell University & $\mathrm{X}$ & $\mathrm{X}$ & $\mathrm{X}$ & $\mathrm{X}$ \\
\hline Iowa State University & $\mathrm{X}$ & & & \\
\hline Michigan State University & & $\mathrm{X}$ & & \\
\hline Ohio State University & & $\mathrm{X}$ & & \\
\hline Pennsylvania State University & & $\mathrm{X}$ & & \\
\hline Purdue University & & $\mathrm{X}$ & & \\
\hline Texas A\&M University & $\mathrm{X}$ & $\mathrm{X}$ & & \\
\hline University of California, Berkeley & & & $\mathrm{X}$ & \\
\hline University of California, Davis & & & $\mathrm{X}$ & \\
\hline University of Florida & $\mathrm{X}$ & $\mathrm{XX}^{\mathrm{x}}$ & $\mathrm{X}$ & $\mathrm{X}$ \\
\hline University of Wisconsin & & $\mathrm{X}$ & & \\
\hline \multicolumn{5}{|l|}{ Non-AAU: } \\
\hline Kansas State University & & & & $\mathrm{X}$ \\
\hline North Carolina State University & & $\mathrm{X}$ & & $\mathrm{X}$ \\
\hline Oregon State University & & $\mathrm{X}$ & & \\
\hline
\end{tabular}

Approximately $60 \%$ of plant science graduate students were domestic and $40 \%$ were international, and this is generally true within the different plant science programs as well (Fig. 1B).

Cellular/molecular biology and breeding/genetics were the two disciplines that had the greatest number of graduate students; $42 \%$ of the total number of graduate students in plant science programs were in one of these two disciplines (Fig. 2). This was followed by plant physiology/biochemistry (15\%), cropping systems/production $(14 \%)$, and ecology (6\%). Other disciplines reported were plant pathol- 
Table 3. The average graduate student enrollment in university plant science programs surveyed in 2003-04.

\begin{tabular}{|c|c|c|c|}
\hline \multirow[b]{2}{*}{ Degree } & \multicolumn{3}{|c|}{ Graduate students/program } \\
\hline & Student no. & Range (no.) & Percent $^{\mathrm{z}}$ \\
\hline MS & $18.8+16.0^{y}$ & $2-70$ & 32 \\
\hline $\mathrm{PhD}$ & $33.2+15.0$ & $12-80$ & 57 \\
\hline MS (non-thesis) & $6.2+19.9$ & $0-90^{\mathrm{x}}$ & 11 \\
\hline Total & $58.1+13.5$ & $32-205$ & $100 \%$ \\
\hline
\end{tabular}

Table 4. The average graduate student enrollment by program at all institutions surveyed in $2003-04$.

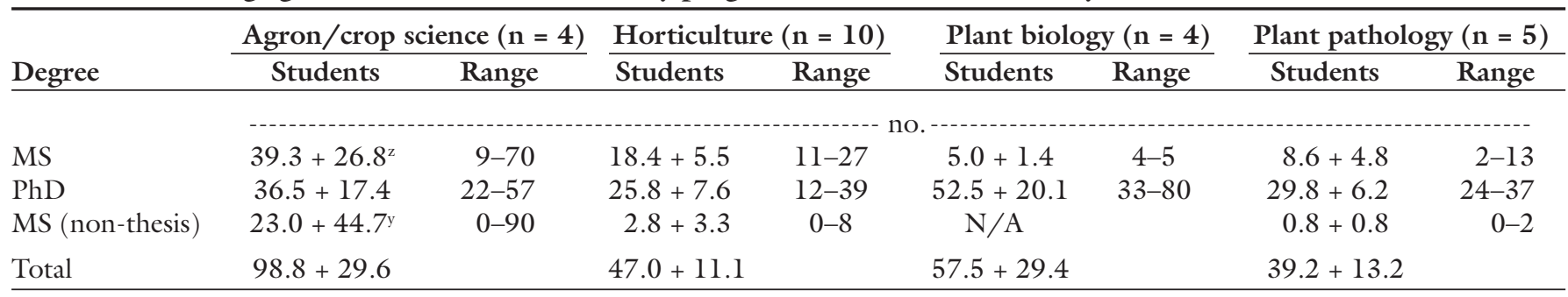

${ }^{\mathrm{z}}$ Mean $+\mathrm{SD}$.

yncludes data from Iowa State, which has 90 MS non-thesis graduate students. The other three programs have 0 or 1 student each.

ogy $(9 \%)$, agronomy (7\%), landscape $(3 \%)$, structure/development $(3 \%)$, and systematics $(<1 \%)$. It was unclear from the responses what discipline(s) the broad areas of plant pathology and agronomy encompassed.

Yearly stipends averaged $\sim \$ 15,750$ and $\$ 17,200$ for MS and PhD graduate students, respectively, in plant science programs overall. However, the range in stipends within a degree was more than $\$ 7,000$ ( $\$ 12,000$ to $\$ 19,900$ for MS and $\$ 14,000$ to $\$ 22,000$ for $\mathrm{PhD}$ stipends). Plant pathology and plant biology programs paid the highest stipends, while stipends in horticulture and agronomy/crop science programs averaged $\sim \$ 1,300$ to $\$ 2,500$ less for MS students and $\sim \$ 2,200$ to $\$ 3,800$ less for PhD students (Table 5 ). Within programs, there was again a broad range in stipend amounts. Stipends in different horticulture programs ranged from $\$ 13,500-\$ 19,373$ for an MS degree, and \$14,000-\$19,373 for a PhD degree. When stipends were adjusted for cost-of-living differences, normalized to cost of living in Gainesville, Fla. (National Association of Realtors, 2004), graduate student stipends in plant biology, especially at the PhD level, were similar to the mean stipends offered by horticulture and agronomy/crop science programs (Table 6). Plant pathology graduate student stipends, however, remained the highest.

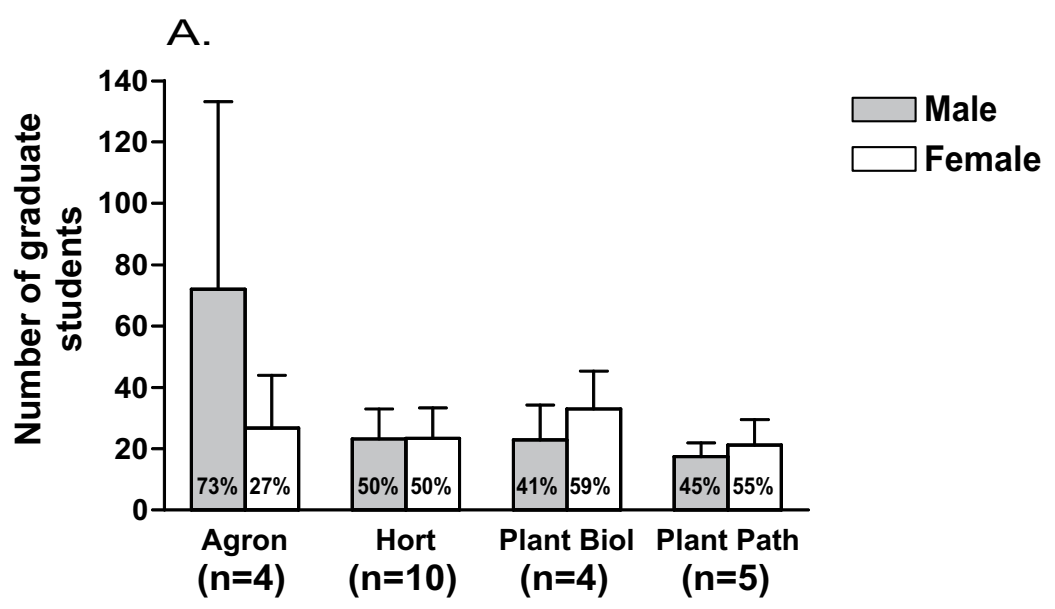

B.

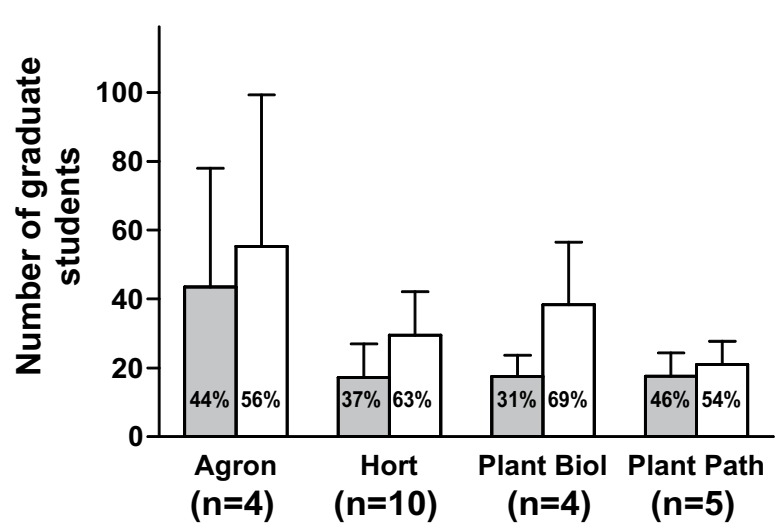

International Domestic

Fig. 1. Graduate student enrollment by gender (A) and citizenship (B) in programs at universities surveyed (Agron $=$ agronomy $/$ crop science, Hort $=$ horticulture, Plant Biol $=$ plant biology, Plant Path $=$ plant pathology $)$. Bars represent mean \pm SD. Numbers in bars for both graphs represent percentage distribution. 


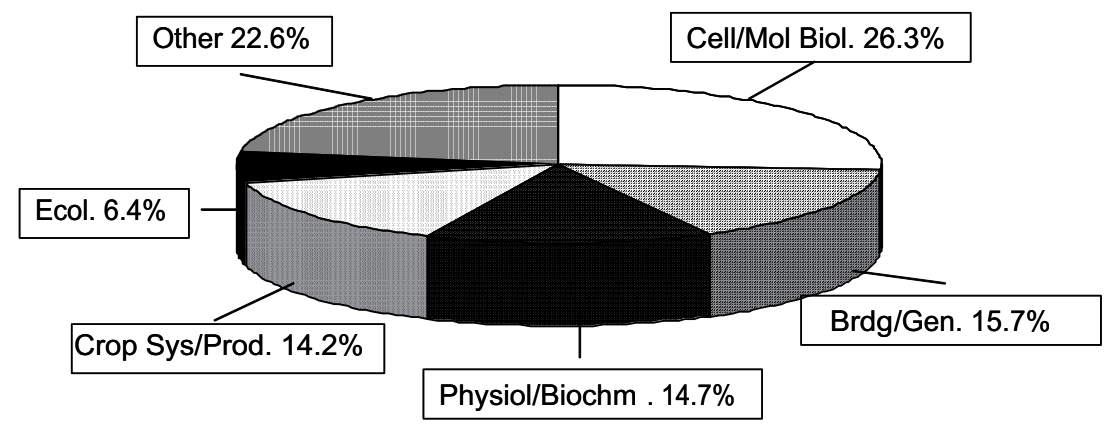

Fig. 2. Percentage of plant science graduate students in each discipline for institutions surveyed. (Cell/Mol Biol. = cell $/$ molecular biology; Brdg/Gen.= breeding $/$ genetics; Physiol $/$ Biochm. = physiology/biochemistry; Crop Sys $/$ Prod. = cropping systems / production; Ecol. = ecology; Other = plant pathology, agronomy, landscape, structure/development, and systematics).

The majority of graduate stipends were paid from grant funds obtained by faculty. Of the programs surveyed, $60 \%$ of stipends came from grant funds, $21 \%$ from state funds, $7 \%$ from foreign governments, $6 \%$ from university fellowships, $2 \%$ from industry, and the rest from miscellaneous sources.

Full tuition waivers were included in graduate student stipend packages at 15 out of the 23 programs surveyed, with partial tuition waivers included in three other programs. Three programs indicated that tuition waivers were not included.

Most programs (61\%) paid health insurance premiums for graduate students. In 10 cases, insurance costs were covered jointly by the department and faculty member, or the university and faculty member. In two cases, the university covered the cost of graduate student health insurance, while in one program, faculty members covered the entire cost of health insurance.

Most programs (13) cited their web page as the primary recruitment tool for graduate students. Other recruitment tools used included invitations to visit the program $(8)$, personal contact by faculty members $(5)$, reliance on the program's reputation (4), advertisements in journals/newsletters (2), and paid summer research opportunities for promising undergraduates (2).

Employment opportunities appear most prevalent in cell/molecular biology and breeding/genetics, as 10 out of 12 responses indicated these two areas as first or second in terms of career potential. Employment opportunities for students graduating in cropping systems/production ranked third, followed by physiology/biochemistry and landscape design. These data are supported by academic, government, and industry positions advertised by American Association for the Advancement of Science, Sciencejobs, American Society of Agronomy, American Society for Horticultural Science, American Society of Plant Biologists, and American Phytopathological Society. Out of 136 permanent plant science positions listed in a 4-month period between Mar. and July 2004, 60 required advanced (primarily $\mathrm{PhD}$ ) degrees in molecular biology/genet$\mathrm{ics} /$ breeding and 48 required advanced (primarily $\mathrm{PhD}$ ) degrees in cropping systems/production. Postdoctoral positions were heavily weighted towards molecularbiology/genetics/breeding, with 60 out of 77 advertised positions in plant science requiring expertise in those areas.

With few exceptions, most programs cited funding as their biggest obstacle to recruiting quality graduate students. The funding issue primarily took the form of non-competitive assistantship salaries (cited by nine programs) and insufficient numbers of assistantships (cited by six programs). However, reduced availability of tuition waivers (cited by four programs) and inability to guarantee multiple years of funding (cited by four programs) were also mentioned. A second obstacle to recruiting quality graduate students was lack of employment opportunities (cited by five programs).

Table 5. The average graduate student stipend by program at all institutions surveyed in $2003-04$.

\begin{tabular}{llllll}
\hline \multirow{2}{*}{ Program } & \multicolumn{2}{c}{ MS } & & \multicolumn{2}{c}{ PhD } \\
\cline { 2 - 3 } \cline { 6 - 7 } & \multicolumn{1}{c}{ Stipend (\$) } & Range $(\$)$ & & Stipend (\$) & Range (\$) \\
\hline Agron/crop sci $(\mathrm{n}=3)$ & $15,186+1,038^{z}$ & $14,000-15,930$ & & $16,423+793$ & $15,930-17,338$ \\
Horticulture $(\mathrm{n}=10)$ & $15,077+2,100$ & $13,500-19,373$ & & $15,819+1,740$ & $14,000-19,373$ \\
Plant biology $(\mathrm{n}=4)$ & $16,500^{y}$ & & & $19,625+2,323$ & $16,500-22,000$ \\
Plant pathology $(\mathrm{n}=4)$ & $17,648+3,180$ & $13,000-19,883$ & & $18,648+2,778$ & $15,000-21,500$ \\
\hline
\end{tabular}

${ }^{2}$ Mean + SD.

yata from University of Florida only.

Table 6. The average cost-of-living adjusted graduate student stipend by program at all institutions surveyed in 2003-04. Stipends were normalized for differences in cost-of-living (\$) using the cost of living in Gainesville, Fla.

\begin{tabular}{lcccc}
\hline Degree & $\begin{array}{c}\text { Agron/crop sci } \\
(\mathbf{n}=\mathbf{3})\end{array}$ & $\begin{array}{c}\text { Horticulture } \\
(\mathbf{n}=\mathbf{1 0})\end{array}$ & $\begin{array}{c}\text { Plant biology } \\
(\mathbf{n}=\mathbf{4})\end{array}$ & $\begin{array}{c}\text { Plant pathology } \\
(\mathbf{n}=\mathbf{4})\end{array}$ \\
\hline MS & $15,827+965^{z}$ & $14,612+1,695$ & $16,500^{y}$ & $18,203+3,647$ \\
PhD & $17,111+231$ & $15,347+1,389$ & $14,999+3,637$ & $19,255+3,559$ \\
\hline
\end{tabular}

${ }^{2}$ Mean + SD.

yata from University of Florida only. 


\section{Discussion}

Historical data clearly indicate that graduate student enrollment in plant science programs throughout the U.S. is decreasing (U.S. Dept of Education, 2001b). The reasons for this are unclear, although financial support is cited by the majority of programs as the greatest obstacle to recruiting high quality students. Direct financial support includes stipend amount, the number of stipends, and duration. There is not, however, a strong correlation between graduate student number and stipend amount. The correlation between the number of $\mathrm{PhD}$ students and stipend amount is significant $(P=0.02)$ but weak $\left(\mathrm{r}^{2}=0.24\right)$, while there is no correlation between the number of MS students (thesis) and stipend amount, or the total number of graduate students (excluding non-thesis MS students) and stipend amount. For example, agronomy/crop science programs generally had the greatest number of graduate students, although stipend amounts were among the lowest. On the other hand, plant pathology programs had the fewest students, but offered the highest stipend amount. There was also no correlation between graduate student number and stipend amount adjusted for the cost-of-living, supporting the perception that cost-of-living differences are not taken into account when students are comparing stipends across programs.

Although historical data on the number of stipends available to support graduate students in plant science programs were not collected, there has been a clear shift from state-supported to grant-supported graduate assistantships. Thus, the financial responsibility is increasingly borne by the individual faculty member. This responsibility includes not only stipend amount, but may also include tuition costs. Tuition fee waiver costs to faculty appear to be having a negative impact on recruitment. As one program indicated, “... faculty are shifting to post-docs due to the total cost of a graduate student. An increase in assistantship monies and/or a decrease in tuition waiver monies would increase student numbers."

Another funding issue which may be detrimentally affecting the ability of some plant science programs to attract graduate students is the lack of paid health insurance. The majority of programs surveyed offer health insur- ance to their graduate students, which makes the package more attractive to prospective students. This, though, is a double-edged sword. Although a graduate student package that covers the cost of health insurance premiums would be more attractive, if the additional costs are carried by the faculty, the total cost of a graduate student would increase even further. This may tend to exacerbate the shifting of faculty away from graduate student training. Overall, shifting the costs of graduate student training (stipend amount, tuition, health insurance) to individual faculty members has resulted in fewer graduate assistantships, as faculty choose to use their funding to hire postdoctoral students and/or technicians.

The ability to recruit graduate students depends not only on funding, but on employment opportunities as well. The greatest numbers of graduate students in plant science programs are in cellular/molecular biology and breeding/genetics and these are the areas with the greatest number of employment opportunities. Comments concerning employment opportunities included "Many students feel that a degree in genetics or plant biology offers more opportunities than a degree in plant pathology" and "Quality students don't perceive horticulture as a career option."

Vigorously promoting career opportunities available for students with advanced degrees in more applied areas (e.g., cropping systems/production) is one approach to increase recruitment in these areas. On the other hand, there is a perception that career opportunities are limited for students with advanced degrees in plant science, particularly in more applied areas. The employment data used in this study indicate approximately 50 positions available (primarily at the $\mathrm{PhD}$ level) in cropping systems / production during a 4-month period. The survey data indicate approximately $200 \mathrm{PhD}$ students currently studying cropping systems/production or physiology/biochemistry. Assuming one-quarter of these students graduate every year, it appears sufficient job opportunities may be available. This is a very rough calculation, however, since job opportunities for a 12 -month period were not determined, and all plant science graduate programs were not surveyed.

For programs that are actively recruiting graduate students, the primary recruitment tool is their website. The importance of a well-designed, easily navigable website cannot be overemphasized. Personal contact by faculty members and invitations to visit the campus/program are also important recruitment tools. Clearly, the burden of graduate student recruitment falls to the program and its individual faculty members, not the college or university. However, as more of the costs of graduate training are shifted to faculty, and funding/resources for research programs are decreasing and becoming harder to obtain, there appears to be an increasing inability and/or reluctance to fund students. Additionally, the shift in research focus, funding, and job opportunities to molecular biology/genetics leaves the more applied research areas particularly vulnerable to low graduate student enrollment. Thus, funding support by the college or university, as well as faculty/departmental awareness of the changing job market, appears essential to continued recruitment of a high quality, diverse plant science graduate program.

\section{Literature cited}

Albrecht, M.L. 1998. ASHS strategic planning and hortbase. Hort Technology 8:316-317.

Dillman, D.A. 2000. Mail and internet surveys: The tailored design method. 2 nd ed. Wiley, New York.

National Association of Realtors. 2004. The salary locator. 12 Jan. 2004. <http://www. homefair.com/homefair/calc/salcalc. html? type $=$ to $>$.

National Science Foundation. 1999. Survey of graduate students and postdoctorates in science and engineering. 7 Dec. 2004. <http://nces.ed.gov/programs/digest/ $\mathrm{d} 01 / \mathrm{dt} 214$.asp $>$.

U.S. Department of Education. 200la. National Center for Education Statistics, higher education general information survey, "Degrees and other formal awards conferred" survey. 7 Dec. 2004. <http://nces.ed.gov/programs/digest/ $\mathrm{d} 01 / \mathrm{dt} 280 . \mathrm{asp}>$

U.S. Department of Education. 2001b. National Center for Education Statistics, integrated postsecondary education data system, "completions" survey. 7 Dec. 2004. <http://nces.ed.gov/programs/digest/ $\mathrm{d} 01 / \mathrm{dt} 259$.asp $>$.

Young, C.E. 2002. The University of Florida's strategic plan. 7 Dec. 2004. <http://www.president.ufl.edu/strategicplan.pdf>. 